\title{
REGRAS PRÁTICAS NA RECONSTRUÇÃO GRÁFICA DAS VASILHAS DE CERÂMICA GUARANI A PARTIR DOS FRAGMENTOS
}

José Proenza Brochado*

Gislene Monticelli**

\section{INTRODUÇÃO}

Um dos problemas contínuos da arqueologia é a reconstrução gráfica das formas das vasilhas a partir de seus fragmentos. Alguns consideram esta tarefa muito difícil, ou mesmo impossível, pelo menos quando se trata de fragmentos pequenos. Defendemos que, comparando com as vasilhas inteiras, a maior parte dos fragmentos de borda permite a reconstrução gráfica da cerâmica Guarani arqueológica, com boa possibilidade de acerto.

Para efetuar a reconstrução gráfica das vasilhas relacionando-as com a sua funcionalidade, seguimos os seguintes passos:

A. A classificação etno-histórica de cerâmica Guarani do século XVII, a partir de Montoya, [1650] 1876, cf. Brochado. In: La Salvia \& Brochado, 1989: 121-145;

* Doutor, Professor na Pontifícia Universidade Católica (PUCRS), em Porto Alegre.

** Lic. e Bel. Ciências Sociais UFRGS), acadêmica de Geografia (UFRGS), mestranda em Arqueologia (PUCRS).

Estudos Ibero-Americanos. PUCRS, v.XX, n.2, p. 107-118, dezembro, 1994 
B. A identificação destas classes entre as vasilhas Guarani arqueológicas inteiras depositadas em museus e coleções, principalmente as do Centro de Estudo e Pesquisas Arqueológicas (CEPA-PUCRS) e as do Laboratório de Arqueologia (UFRGS);

C. O estabelecimento das regras de proporção entre as partes destas vasilhas, separadamente para cada classe; ver Brochado, Monticelli \& Neumann In: Veritas, 1990: 727-743;

D. O uso destas formas na reconstrução gráfica através de fragmentos.

Os três primeiros passos já foram efetuados e seus resultados publicados. As regras resultantes foram utilizadas, em larga escala, no estudo do material obtido durante as pesquisas do Projeto Arquelógico Uruguai, convênio entre a ELETROSUL (Centrais Elétricas do Sul do Brasil)e a PUCRS (Pontifícia Universidade Católica do Rio Grande do Sul), mas os resultados só constam nos relatórios entregues à financiadora do projeto. (La Salvia, Brochado \& Naue. Naue, 1989 e La Salvia \& Brochado, 1990).

Neste trabalho indicaremos quais as regras práticas que foram sendo estabelecidas ao longo das pesquisas, através do estudo de mais de $5 \mathrm{mil}$ fragmentos de bordas.

Para encontrarmos a funcionalidade das vasilhas de cerâmica Guarani, recuperadas arqueologicamente, recorremos à analogia etnográfica obtida a partir das descrições encontradas no Dicionário Guarani-Espanhol de Antônio Ruíz de Montoya ([1650] 1876).

Montoya indica a existência de diversas classes de vasilhas em uso entre os Guarani e cita suas funções. Na maior parte das vezes o termo em espanhol foi suficiente para dar uma idéia da forma, por exemplo, yapepó = olla $=$ panela. Inferências como esta foram feitas também para as outras classes de vasilhas no Glossário que faz parte do livro Cerâmica Guarani (La Salvia \& Brochado, 1989: 125-145), onde há a comparaçāo dos termos em Guarani com os termos em Espanhol e a explicação destes através de comentários.

Identificamos pelo menos seis classes de vasilhas Guarani entre àquelas descritas por Montoya. São elas:

1 - panelas para cozinhar (yapepó);

2 - caçarolas para cozinhar (ñaẽtá ou ñãé);

3 - pratos para assar beiju (ñamõpũ ou ñamypiu)'

4 - jarras para bebidas em geral, especialmente bebidas fermentadas alcoólicas (cambuchî);

5 - pratos para comer (ñaẽmbé ou teembirú); 


\section{6 - tigelas para beber (cambuchí caguãba).}

Identificamos estas classes entre as vasilhas de cerâmica Guarani inteiras, depositadas em museus e coleções, e por comparação com estas foi possível reconstruir graficamente a forma daquelas vasilhas que estão representadas apenas pelos seus fragmentos.

Conforme a porção da área total da vasilha, representada pelo fragmento da borda usado na reconstrução, estabelecemos critérios restritos de como agir em cada caso.

Estes critérios serão explicitados a seguir para cada classe de vasilha (entendendo por classe, todas as vasilhas que teriam a mesma função).

É importante observar que as reconstruções gráficas servem apenas para indicar algumas possibilidades de forma e dimensões dentro de cada categoria (vasilhas da mesma classe, que só se diferenciam por pequenas variações na posição e perfil da borda). Isto não indica que, a partir de um fragmento da sua borda, possamos conhecer a forma exata que a vasilha teria tido. O que, porém, não prejudica nossa classificação, uma vez que nossa preocupação é com a reconstrução da funcionalidade das vasilhas.

As seis classes de vasilhas Guarani identificadas são (Figura 1):

\section{Yapepó:}

No dicionário de Montoya (cf. Brochado), as vasilhas usadas para a preparação de alimentos por fervura sobre o fogo, aparecem mencionadas como yapepó, e são descritas como tendo formas bojudas, com bordas côncavas, verticais ou inclinadas para fora.

Montoya traduz o termo yapepó pelo vocábulo espanhol olla, que em português corresponde à panela. Dicionários de espanhol ilustram a forma mais freqüente das panelas tradicionais: um recipiente esferoidal, com as paredes infletidas e a borda inclinada para fora, com dimensões variadas. As panelas européias antigas realmente correspondem a esta descrição, exceto pelo fato de possuirem alças e apoios em forma de patas.

Não foi difícil reconhecer a classe das vasilhas denominadas yapepó nos conjunto das vasilhas inteiras de cerâmica Guarani arqueológicas. De fato, são muito comuns os recipientes de base conoidal e paredes infletidas, com bojo bem marcado e borda côncava, vertical ou inclinada para fora, que salvo os detalhes, parecem homólogos das panelas européias. Concluímos, então, que deveriam ser estas as vasilhas a que Montoya se referia ao citar o termo yapepó. 


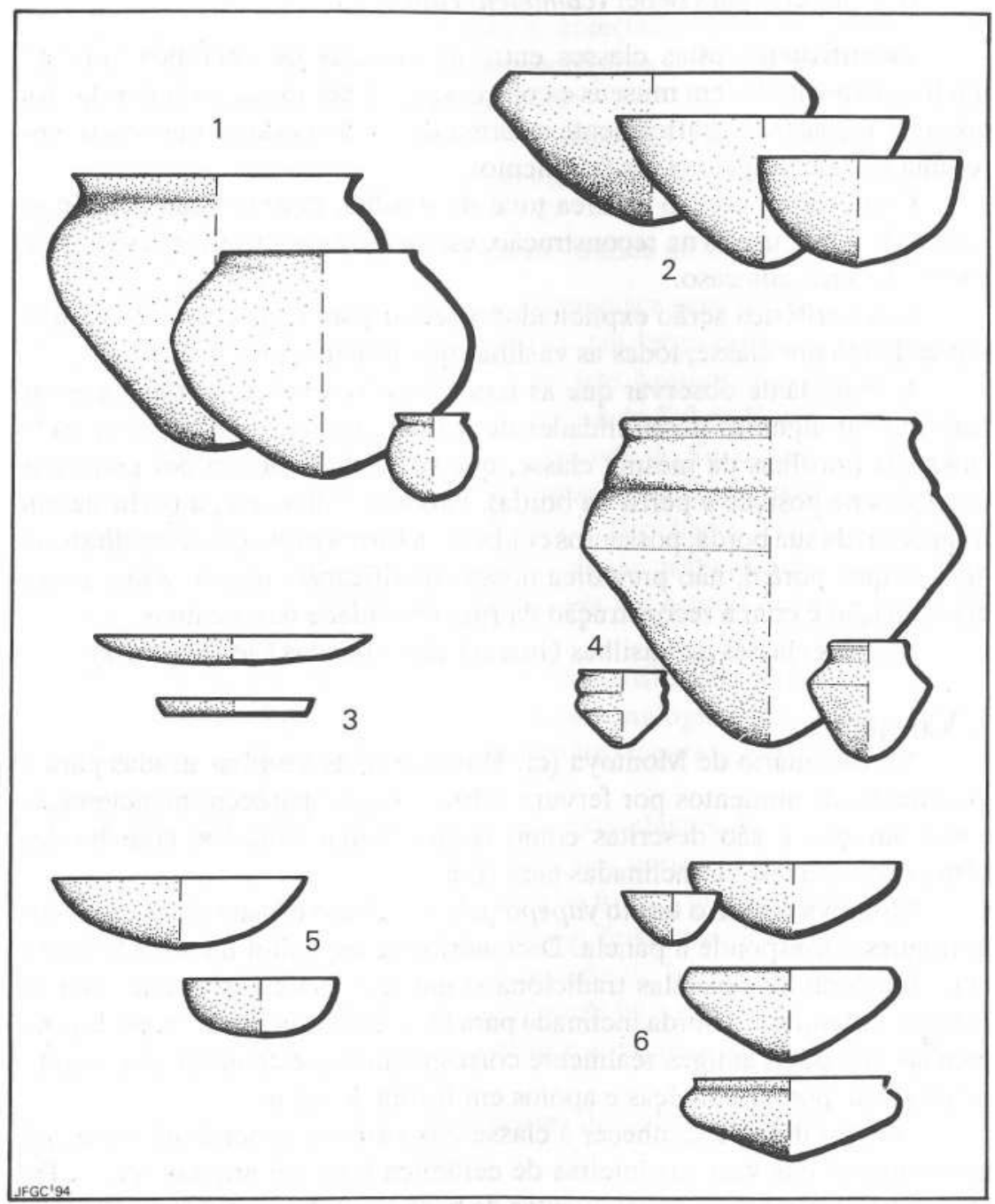

FIGURA 1: Principais formas das vasilhas de cerâmica arqueológica Guarani, divididas em seis classes: 1 . panela $=$ yapepó; 2 . caçarola $=$ ñaẽtá; 3 . prato para assar $=\tilde{n} a m o ̄ p i u \tilde{i}$; 4. jarra para bebida $=$ cambuchí $;$. prato para comer $=\tilde{n} a \tilde{e} m b e ́ ;$. 6 tigela para beber $=$ cambuchí caguabá. 


\section{1.a. Bordas:}

Montoya identificou duas variedades de bordas nesta classe de vasilhas: a vertical e a inclinada para fora; assim como encontramos nos exemplos arqueológicos. Nas vasilhas inteiras, cuja forma se assemelha ao yapepó, se observa que apresentam uma variação na posição da borda que vai ligeiramente inclinada para dentro, passando pelas verticais, até as inclinadas para fora.

\section{1.b. Base:}

Montoya define duas categorias de yapepó quanto à forma da base: conoidal e arredondada, e assim procuramos representá-las ao fazer a sua reconstrução gráfica.

\section{1.c. Dimensões:}

Montoya classificou os yapepó quanto as dimensões em pequenos, médios e grandes. Partindo desta informação e observando as variações nas dimensōes do diâmetro nas vasilhas inteiras e fragmentos de borda, convencionamos classificar como pequenos (yapepó mỹri) aqueles com o diâmetro de boca entre 12 a $16 \mathrm{~cm}$; médios (yapepó boyá) de 18 a $30 \mathrm{~cm}$ e grandes (yapepó guaçú), maiores de $32 \mathrm{~cm}$. As vasilhas da mesma forma, mas com o diâmetro da boca menor que $12 \mathrm{~cm}$ foram classificadas como miniaturas (porque dificilmente poderiam ter sido usadas para a preparação de alimentos sobre o fogo.

\section{1.d. Função:}

A função do yapepó como panela de cozinhar fica clara nas diversas frases e expressōes mencionadas por Montoya (cf. Brochado), onde o termo é relacionado com a preparação dos alimentos por fervura.

\section{1.e. Critérios para a reconstrução gráfica:}

Reconstruimos graficamente, como yapepó, todos os fragmentos infletidos que apresentam borda côncava, seguida por um bojo arredondado. A borda pode ser vertical, ligeiramente inclinada para dentro ou para fora, predominando esta últimas. Excetuam-se aquelas bordas côncavas cuja posição ou a posição da inflexão da parede que se segue, requer sua reconstrução como tigela. É bom lembrar que tigelas infletidas com a borda côncava inclinada para fora são raras entre as vasilhas inteiras.

Na reconstruçäo gráfica representamos todos os yapepó com o bojo pronunciado, preferentemente arrendondado do que carenado, porque esta 
é uma característica de sua forma, e todos com bases conoidais, só foram utilizadas no caso das miniaturas, conforme se observa nas vasilhas inteiras.

Excluem-se da classe dos yapepó aqueles fragmentos pintados interna ou externamente, que foram classificados como cambuchí com forma de yapepó (ver cambuchî), porque estes obviamente não poderiam ter sido usadas sobre o fogo.

\section{Naẽtá:}

Montoya traduz ñaẽtá pelo termo espanhol cazuela, isto é, caçarola. Estas vasilhas européias tinham uma forma aproximadamente tronco-cônica, com borda direta, contínua com a parede, aproximadamente vertical ou inclinada para fora e base aplanada ou levemente arredondada. Como a caçarola, o ñaẽtá serviria para cozinhar alimentos por fervura sobre o fogo.

Nas coleções de vasilhas Guarani inteiras, recipientes abertos, de forma conoidal ou elipsoidal, com dimensões relativamente grandes, apare-

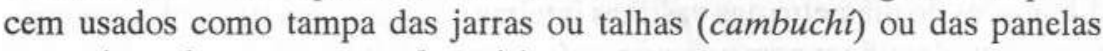
yapepó, usadas como urnas funerárias.

\section{2.a. Dimensões:}

Montoya classifica os ñaẽtá quanto às dimensões em tamanho normal (ñaẽtá) e grande (ñaẽtá guaçu). Convencionamos como medianos aqueles com o diâmetro da boca variando de 30 a $48 \mathrm{~cm}$, e grandes aqueles com diâmetro maior de $50 \mathrm{~cm}$.

\section{2.b. Critérios para a reconstrução gráfica:}

Reconstruimos graficamente como ñaẽtá, os fragmentos da borda contínua com a parede, ligeiramente inclinada para fora, vertical ou inclinadas para dentro, às vezes levemente infletida, que tenham as dimensões necessárias.

Excluem-se as bordas pintadas interna e/ou externamente, pelo mesmo motivo já considerado para os yapepó. Estas são reconstruídas como tigelas, representadas com menor profundidade do que se tivessem sido representadas como ñaẽtá.

\section{3. Ñamôpyũ:}

Montoya denomina ñamôpyũ ou ñamỹpiu uma classe de vasilhas cujo nome traduz por tostador ou torrador, com toda a probabilidade de estar se referindo aos pratos rasos para torrar farinha de mandioca e/ou assar o beiju. 
Nas coleçōes de vasilhas inteiras são raramente encontrados, porque, como os pratos de comer (tembiiru), não faziam parte dos sepultamentos, nem como urnas para contê-los, nem postos no interior destas.

No entanto, o ñamôpyũ são fáceis de serem identificados devido a borda convexa muito baixa ou apenas vestigial, formando uma espécie de prato ou tigela muito rasa.

\section{3.a. Dimensões:}

Montoya divide os tostadores em de tamanho normal (ñamôpỹ̃) e grandes (ñamôpyũ guaçu). Convencionamos como normais aqueles com diâmetro da boca variando de 18 a $32 \mathrm{~cm}$ e grandes aqueles com diâmetro maior de $34 \mathrm{~cm}$. Vasilhas com a mesma forma, porém, com diâmetro igual ou menor de $12 \mathrm{~cm}$, que por suas dimensões não deveriam ter a mesma função, foram classificadas como miniaturas da sua classe.

\section{3.b. Critérios para a reconstrução gráfica:}

Os ñamôpyũ são representados com base plana ou levemente arredondada, conforme sugere o próprio fragmento. Excluem-se as bordas pintadas interna ou externamente, pelo mesmo motivo já considerado para os yapepó e ñaẽtá. Estas são reconstruídas como pratos ou tigelas rasas.

\section{Cambuchí:}

Montoya denomina cambuchí a vasilha utilizada para conter líquidos; principalmente aquelas para servir bebidas fermentadas alcoólicas, mas também, possivelmente as usadas para guardar água.

$\mathrm{O}$ termo cambuchí foi traduzido indiferentemente pelos vocábulos espanhóis: tinaja, cântaro e jarro, correspondendo em português a talha, cântaro e jarro. As formas européias têm em comum a forma elipsoidal vertical ou duplo-cônica, com o diâmetro maior situado no bojo, acima da metade da altura, base conoidal, parte superior restringida formando um pescoço e borda extrovertida.

Os cambuchí foram identificados como vasilhas usualmente pintadas e de grandes dimensões, encontradas enterradas nos sítios arqueológicos, com evidência de terem sido usadas para sepultamento primários ou secundários. Seu uso anterior para preparar e servir bebidas fermentadas alcoólicas ou para armazenar água sempre foi aceito, com base em evidências etnográficas.

Estas vasilhas tem a forma de jarras ou talhas, de contorno complexo, segmentado, como vasilhas sobrepostas, com vários pontos de ângulo, o 
mais baixo deles, correspondendo ao maior diâmetro e situado acima da metade da altura. Estes pontos de ângulo formam o que se denomina carena ou carenagem e a segmentação pode se repetir até 3 vezes, formando o que se denomina "ombros".

\section{4.a. Bordas:}

O termo usado por Montoya para a borda do cambuchí é diferente dos termos usados para as bordas do yapepó. Isso se relaciona provavelmente ao fato das vasilhas inteiras, que podem ser identificadas com a definição do cambuchí, apresentarem geralmente borda carenada ou reforçada externamente. A borda côncava extrovertida, que como vimos é característica do yapepó, aparece mais raramente nas urnas funerárias pintadas, que então foram descritas como cambuchí com forma de yapepó.

\section{4.b. Boca:}

Montoya divide os cambuchí entre os de boca estreita e os de boca mediana. Esta divisão, observável nas vasilhas inteiras, não pode ser usada quando não é possível considerar a relação entre o diâmetro da boca e o diâmetro do bojo.

\section{4.c. Base:}

Montoya também divide o cambuchí pela forma da base, existindo os de base conoidal, arredondada e aplanada. Esta divisão, observável nas vasilhas inteiras, também não pode ser aplicada na reconstrução do material fragmentado, porque não podemos relacionar a forma das bases com as respectivas bordas.

\section{4.d. Dimensões:}

Montoya dividiu os cambuchí, quanto as dimensões, em pequenos e grandes. Convencionamos classificar como pequenos (cambuchí miri) aqueles com o diâmetro da boca variando de 18 a $34 \mathrm{~cm}$ e como grandes (cambuchí guaçú) aqueles com diâmetro maior de $36 \mathrm{~cm}$. As vasilhas da mesma forma, mas menores de $12 \mathrm{~cm}$ e que não deveriam ter a mesma função, foram consideradas miniaturas.

\section{4.e. Critérios para a reconstrução gráfica:}

A maioria das bordas carenadas, reforçadas externamente, pintadas ou não, são reconstruídas graficamente na forma de cambuchí, excetuando-se 
aquelas cuja inclinação da borda ou posição da inflexão da parede que se segue requer sua reconstruçāo como tigela

Na reconstrução gráfica, os cambuchí foram representados com um bojo pronunciado, preferentemente carenado do que arredondado, porque esta é uma característica de sua forma.

Alguns são representados com a base conoidal, outros, mais raramente, com a base arredondada. Nas vasilhas inteiras da área estudada (RS e SC) não aparecem bases aplanadas, as quais existem porém em São Paulo e no Paraguai.

As miniaturas dos cambuchí são reconstruídas com forma esferoidal, porque assim se apresentam nas coleções.

Montoya descreve outro tipo de cambuchí, o cambuchí yaruquai, que deveria ser constringido na parte média, formando corpo duplo. Realmente são encontrados fragmentos de borda e que podem ser reconstituídos com esta forma. Na região do Alto Uruguai, onde existem, tem a superfície alisada e enegrecida por esfumaçamento.

\section{5. e 6. Tigelas:}

\section{Ñaẽmbé ou tembïru e cambuchí caquâbá.}

Montoya denomina ñaẽmbé ou tembiiru uma classe de vasilhas, cujo nome traduz por prato, louça; implicando seu uso para comer. O termo tembïru é traduzido como prato, claramente derivado de tembiú, comida. Este uso indica a existência de pratos coletivos ou comunais, conforme a expressão: "o que come comigo em um prato".

Os ñaẽmbé são fáceis de serem identificados devido a sua forma: pratos e tigelas muito abertas, com a borda convexa, contínua com as paredes, aproximadamente vertical ou inclinada para fora. São, no entanto, raramente encontrados nas coleções de vasilhas inteiras, porque não faziam parte dos sepultamentos.

Montoya indica a existência de outra classe de recipientes, vasilhas de beber (cambuchí caguaba), cujo nome traduz como: vaso onde se bebe vinho, instrumento de beber. Este termo está relacionado também com os cambuchí miri, traduzido por copo ou vaso, mas que em sentido genérico, poderia ser qualquer vasilha em que se bebe. Montoya, porém, não descreve o cambuchí caguâba, nem dá qualquer sugestão a respeito de sua função. $\mathrm{O}$ uso do termo cambuchí como parte do nome não parece indicar a forma, pois aparentemente, podia ser usado para qualquer vasilha relacionada à preparação, serviço ou consumo de bebidas. 
Através da analogia etnográfica se chegou a conclusão que as vasilhas de beber dos Guarani deveriam ter a forma de tigelas, tanto aquelas feitas de cerâmica, como as de cuia. Neste caso, se observa nas coleçōes um grande número de recipientes pintados externamente e mesmo internamente, às vezes de contorno muito elaborado e que faziam parte quase que obrigatória do acompanhamento dos restos humanos nas urnas funerárias.

Sendo ambas as classes - ñaẽmbé ou tembiiru e cambuchí caguâbacompostas por tigelas, fica difícil diferenciá-las a partir dos fragmentos da borda. O que se percebe ao observar vasilhas inteiras é que se distinguiram principalmente pela forma da base: os ñaẽmbé ou tembiiru possuiriam base aplanada ou levemente arredondada, enquanto os cambuchí caguâba apresentariam base periférica, elipsoidal ou conoidal.

\section{5.a. Dimensões:}

Montoya classifica os ñaẽmbé ou tembiiru em pequenos e grandes. Convencionamos classificar como pequenos aqueles com diâmetro da boca de 12 a $16 \mathrm{~cm}$, medianos aqueles com diâmetro de 18 a $26 \mathrm{~cm}$ e grandes, aqueles com diâmetro de 28 a $34 \mathrm{~cm}$. As vasilhas menores do que $12 \mathrm{~cm}$ de diâmetro da boca foram consideradas miniaturas e não teriam a mesma função de prato de comer.

Assim haveriam pratos individuais (pequenos), pratos usados por pequenos grupos (medianos) e pratos comunais (grandes) usados por grupos maiores.

6.a

Para os cambuchí caguâba não há informações quanto a dimensão. Consideramos como pequenas as tigelas com o diâmetro da boca, entre 12 e $16 \mathrm{~cm}$, medianas, as de 18 a $26 \mathrm{~cm}$ de diâmetro da boca foram consideradas miniaturas e não teriam a mesma função.

\section{5.b. e 6.b. Bordas:}

As bordas diretas, isto é, contínuas com as paredes, convexas, ligeiramente inclinadas para dentro foram reconstruídas como tigelas, sempre que sua posição assim o sugeria.

Uma maneira de diferenciá-las com certo grau de probabilidade, foi usar o critério da relação diâmetro-profundidade (altura). Assim as mais rasas $(2,4$ a 4,5$)$ seriam pratos de comer (ñãmbé ou tembiiru) e as mais profundas $(0,5$ a 2,49$)$, tigelas de beber (cambuchí caguâba). 
Também foram reconstruídos como tigelas de beber aquelas bordas infletidas ou complexas, carenadas, cuja posição assim o sugeria; uma vez que nas vasilhas inteiras estes perfis de borda aparecem unicamente naquelas tigelas que podem ser interpretadas como tendo esta função.

Na reconstrução gráfica as bases são representadas levemente arredondadas ou aplanadas para os pratos de comer e esferoidais, elipsoidais ou conoidais para as tigelas de beber, conforme se observa nas vasilhas inteiras.

Entre as vasilhas Guarani inteiras, existem ainda outras formas que não podem ser incluídas nas seis classes morfológico/funcionais que identificamos acima. Estas vasilhas, porém, são raras e parecem estar limitadas à determinadas áreas. Muitas destas vasilhas aparecem ilustradas, por exemplo, no livro "Cerâmica Guarani" (La Salvia \& Brochado, 1989).

É grande a importância na reconstrução gráfica e da inferência sobre a funcionalidade das vasilhas, principalmente, nas tentativas de identificar qual teria sido a alimentação pré-histórica, tanto qualitativa, como quantitativamente. Do ponto de vista qualitativo, quais seriam os tipos de alimentos, como eram preparados e consumidos; e, quantitativamente, pela contagem das vasilhas identificadas, estimar os números mínimo e máximo da população nas aldeias, hoje representadas por sítios arqueológicos.

Agradecemos a João Felipe Garcia da Costa pela arte-final da ilustração.

\section{BIBLIOGRAFIA}

BROCHADO, j. p., MONTICELLI, G., NEUMANN, E. Analogia etnográfica na reconstrução gráfica das vasilhas Guarani arqueológicas. In: Veritas. Porto Alegre, v. 35 , n. 140 , dez. 1990. p. 727-43.

LA SALVIA, F., BROCHADO, J. P. Cerâmica Guarani. Porto Alegre: Posenato Arte e Cultura, 1989. p. 121-45.

LA SALVIA, F., BROCHADO, J. P., NAUE, G. (coords.) Relatório Projeto Guarabi. Levantamento Cultural, histórico, arqueológico e paisagístico. Projeto Arqueológico Uruguai. Porto Alegre, CEPA/PUCRS-ELETROSUL, 1988. p. 204-15.

LA SALVIA, F., BROCHADO, J. P., NAUE, G. Programa para o salvamento do patrimônio histórico-cultural. Rio Uruguai. Área de Machadinho. Projeto Arqueológico Uruguai. Convênio ELETROSUL-CEPA/PUCRS, Porto Alegre, 1989. p. 7741190.

LA SALVIA, F., BROCHADO, J. P. Patrimônio histórico-cultural. Rio Uruguai. Área de Garabi. ELETROSUL/PUCRS. Porto Alegre, 1990. p. 246-314. 
MONTOYA, Antônio Ruíz de. Vocabulário y tesoro de la lengua guaraní ó mas bien tupi. I: Vocabulário español-guaraní (ó Tupi)-español. Nueva edición: Viena, Faesy y Frick; Paris, Maisonneuve y Cia. 1876 (1640). Edição organizada por F. A. Vernhagen, Visconde de Porto Seguro. 